\title{
Neuroendocrine tumors of the lung: Has the stage been set?
}

\author{
Stephen R. Broderick, MD, MPHS
}

\footnotetext{
From the Division of Thoracic Surgery, Department of Surgery, Johns Hopkins University School of Medicine, Baltimore, Md.

Disclosures: Dr Broderick is on the steering committee for a Bristol-Meyers-Squibb clinical trial, but it is unrelated to this topic.

Received for publication Sept 7, 2017; accepted for publication Sept 8, 2017; available ahead of print Nov 10, 2017.

Address for reprints: Stephen R. Broderick, MD, MPHS, 600 N Wolfe St, Blalock 240, Baltimore, MD 21287 (E-mail: sbroder7@jhmi.edu).

J Thorac Cardiovasc Surg 2018;155:414-5

$0022-5223 / \$ 36.00$

Copyright $(5) 2017$ Published by Elsevier Inc. on behalf of The American Association for Thoracic Surgery https://doi.org/10.1016/j.jtcvs.2017.09.023
}

The ability to classify stage of disease is fundamental to the counseling and treatment of patients with cancer. It is the common language that we use to describe anatomic findings and extent of disease. It is essential in the comparison of patients and treatments, aiding in treatment selection and estimation of prognosis.

Neuroendocrine tumors of the lung are a group of pulmonary tumors with a spectrum of histologic and clinical features ranging from indolent low-grade tumors (typical carcinoid) to more aggressive intermediate-grade (atypical carcinoid) and high-grade tumors (large cell neuroendocrine). These tumors exhibit distinct histologic and molecular features that distinguish them from the more common adenocarcinoma and squamous cell carcinomas of the lung. ${ }^{1}$ Historically, the American Joint Committee on Cancer non-small cell lung cancer (NSCLC) TNM staging system was often applied to neuroendocrine tumors. This convention was supported by the 2008 recommendation of the International Association for the Study of Lung Cancer (IASLC) Staging Project that the 7th edition of TNM be applied to bronchopulmonary carcinoid tumors. ${ }^{2}$ In fact, in its evaluation of proposed changes to the TNM system, the IASLC Staging Project assesses the applicability of the 8th edition across the spectrum of lung cancer histologic types. This analysis has been completed for small cell carcinoma compared with NSCLC as well as NSCLC subtypes, but has not yet been reported for neuroendocrine tumors. $^{3}$

In this issue of the Journal, Cattoni and colleagues ${ }^{4}$ report on a multi-institutional data set of patients who underwent resection of a primary neuroendocrine tumor of the lung between 2000 and 2015. They used proportional hazards modeling to identify factors associated with diseasespecific survival after resection and to propose a diseasespecific staging system. A total of 510 patients were included in the analysis, and Cattoni and colleagues ${ }^{4}$ conclude that $\mathrm{T}$ stage and histologic grade are the 2 main factors associated with survival. These factors were then incorporated into a revised staging system for neuroendocrine tumors. It is striking that nodal status was not associated with survival. nostic factor. important topic.

\section{References}

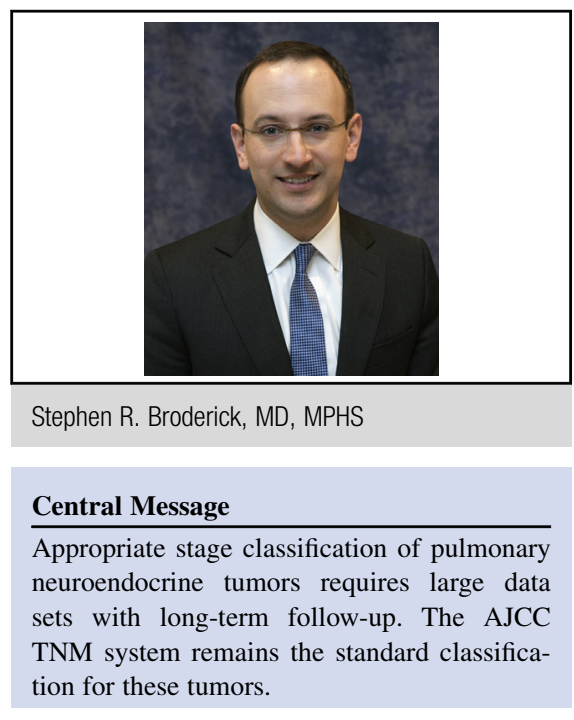

See Article page 405 .

Cattoni and colleagues' main point is well taken. ${ }^{4} \mathrm{~T}$ stage is important in neuroendocrine tumors-particularly in low-grade tumors (the majority in this data set). This was also identified in the 2008 analysis by Travis and associates ${ }^{2}$ of the Surveillance, Epidemiology, and End Results Program and IASLC databases. As Cattoni and colleagues ${ }^{4}$ conclude, histologic grade of tumor is an important prog-

The data set is limited by the fact that it contains only 98 patients with nodal disease (19\%) and 51 deaths (10\%). The notion that nodal status is not associated with survival should therefore be interpreted with caution. The proposed stage groups are based on very few events, resulting in wide confidence intervals for stage-specific survival. Finally, although 51-month median follow-up is laudable, this may be too short to discern between stage groups in neuroendocrine tumors, particularly those that are of low or intermediate grade.

This article of Cattoni and colleagues ${ }^{4}$ highlights the difficulty in studying an uncommon neoplasm with relatively good outcomes. The TNM system remains the standard classification for this tumor until a superior system is developed and validated. The analysis of applicability of the 8 th edition TNM across the histologic spectrum from the IASLC staging project should shed more light on this

1. Travis WD. Pathology and diagnosis of neuroendocrine tumors: lung neuroendocrine. Thorac Surg Clin. 2014;24:257-66. 
2. Travis WD, Giroux DJ, Chansky K, Crowley J, Asamura H, Brambilla E, et al; International Staging Committee and Participating Institutions. The IASLC Lung Cancer Staging Project: proposals for the inclusion of broncho-pulmonary carcinoid tumors in the forthcoming (seventh) edition of the TNM Classification for lung Cancer. J Thorac Oncol. 2008;3:1213-23.

3. Detterbeck FC, Chansky K, Groome P, Bolejack V, Crowley J, Shemanksi L, et al; IASLC Staging and Prognostic Factors Committee, Advisory Boards, and Participating Institutions. The IASLC Lung Cancer Staging Project: methodology and validation used in the development of proposals for revision of the stage classification of NSCLC in the forthcoming (eighth) edition of the TNM Classification of Lung Cancer. J Thorac Oncol. 2016;9: 1433-46.

4. Cattoni M, Vallières E, Brown LM, Sarkeshik AA, Margaritora S, Siciliiani A, et al. Improvement in TNM staging of pulmonary neuroendocrine tumors requires histology and regrouping of tumor size. J Thorac Cardiovasc Surg. 2018;155: 405-13. 